\title{
ROUX-EN-Y GASTROENTEROANASTOMOSIS IN THE TREATMENT OF STENOSING AND ADVANCED GASTRIC ADENOCARCINOMA
}

\author{
Gastroenteroanastomose em Y de Roux no tratamento do adenocarcinoma gástrico avançado e \\ estenosante
}

Nelson Adami ANDREOLLO, Luiz Roberto LOPES, João de Souza COELHO NETO, Henrique José Virgili SILVEIRA

From the Department of Surgery and Gastrocentro - School of Medical Sciences, State University of Campinas - UNICAMP, Campinas - SP and Hospital Estadual de Sumaré, Sumaré, SP, Brazil.

DESCRITORES - Neoplasias gástricas. Adenocarcinoma. Cirurgia.
RESUMO - Introdução - O câncer gástrico é a neoplasia mais frequente do trato digestivo e cerca de $60 \%$ dos casos são avançados quando o doente é admitido pela primeira vez para tratamento. Objetivo - Análise retrospectiva de doentes com adenocarcinoma gástrico avançado, estenosante e irressecável, realizando gastroenteroanasmose em Y de Roux. Métodos - Entre janeiro de 1998 a dezembro de 2009, 62 doentes foram operados, com idade média de 52,7 anos, sendo 43 masculinos (69.3\%). A anastomose gastrojejunal foi látero-lateral e pré-cólica, e a jejuno-jejunoanastomose término-lateral em Y de Roux, distando cerca de 50 cm do estômago. Resultados - O tempo médio de hospitalização foi de 7,5 dias. Foi registrado um óbito secundário a pneumonia e sepse (1.6\%). No pós-operatório todos os doentes passaram a ingerir alimentos sólidos e pastosos, apresentando ganho de peso. A ocorrência de vômitos frequentes foi encontrada em quatro doentes (6,4\%). A sobrevida média foi de 11 meses. Conclusão - A gastrojejunoanastomose em Y de Roux é boa opção para impedir a ocorrência de vômitos biliosos e entéricos no pós-operatório de operação paliativa, promovendo ganho de peso e melhorando a qualidade de vida dos doentes.

ABSTRACT - Background - Gastric cancer is the most common cancer of the digestive tract and approximately $60 \%$ of cases are advanced when the patient is first admitted for treatment. Aim- A retrospective analysis of patients with advanced gastric adenocarcinoma, stenosing and unresectable, performing Roux-en-Y gastroenteroanasmosis. Methods - From January 1998 to December 2009, 62 patients were operated with a mean age of 52.7 years, being 43 males (69.3\%). The gastrojejunal anastomosis was latero-lateral, pre-colic and jejuno-jejunoanastomosis end-to-side Roux-en-Y, lying about $50 \mathrm{~cm}$ from the stomach. Results - The average hospital stay was 7.5 days. It was reported one death secondary to pneumonia and sepsis (1.6\%). Postoperatively, all patients started to eat solids and pastes, with weight gain. The occurrence of frequent vomiting was found in four patients $(6,4 \%)$. The median survival was 11 months. Conclusion - The Roux-en-Y gastroenteroanastomosis is a very good option to prevent the occurrence of enteric and bilious vomiting after palliative surgery, causes weight gain and improved quality of life.
HEADINGS - Stomach neoplasms. Adenocarcinoma. Surgery.
INTRODUCTION

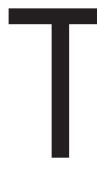

he gastric cancer is the most frequent neoplasia of the digestive tract and about $60 \%$ of the cases are advanced tumours, when patients are firstly admitted in out-patient ambulatory. The incidence of the disease decreased in some countries to occupy the second position and is currently the third most common malignant tumor worldwide, with approximately 870000 new cases per year. In men, the incidence is twice higher than in women. The geographical distribution of stomach cancer is characterized by its wide international variation. The country with the highest incidence is Japan (77.9 per 100.000 in men and 33.3 per 100.000 in women), but high rates are also observed in Central America, South America and East Asia.In China, it is the highest incidence (43.7 per 100,000 in men and 18.9 per 100,000 in women) $)^{1,2,3}$.

In Brazil, official records show that cancer rates highest average annual age-adjusted incidence per 100000 men were found in São Paulo - SP (19971998: 38.8), Federal District - DF (1996 to 1998: 32, 7) and Belém - PA (1996- 
1998: 27.6). In the female population, the highest rates were observed in São Paulo (1997-1998: 15.0), Federal District (1996-1998: 14.7) and Belém (1996-1998: 10.8). The lowest rates were observed in the cities of João Pessoa - PB (1999-2000) in men (8.6) and Salvador - BA (1997-2001) in women (4.8)3.

The National Cancer Institute estimates in 2003 an incidence of 16.4 males and 7.38 females suffering from these type of cancer, for 100.000 inhabitants $^{3,4}$.

The adenocarcinoma is the most commom histopatologic type. Considering the gastric location, the tumour is most common in the lower part of the stomach, followed by middle and the upper part ${ }^{1,4}$.

The best choice is a surgical and radical treatment, performing a subtotal or a total gastrectomy associated to an extended lymph node dissection, performing a DII lymphadenectomy ${ }^{4,5}$.

However, if the patients have an unresectable, stenosing and advanced tumour, are indicated palliative surgeries. The classic operation employed when the lesion is located in the lower part of the stomach is a latero-lateral gastroenteroanastomosis (Figure 1), that facilitates the gastric emptying, but frequently causes reflux of enteric contents into the stomach and the patients complains of epigastric pain and burnings. To avoid these symptoms another option is a Roux-en-Y latero-lateral gastroenteroanastomosis ${ }^{4,6,7}$.
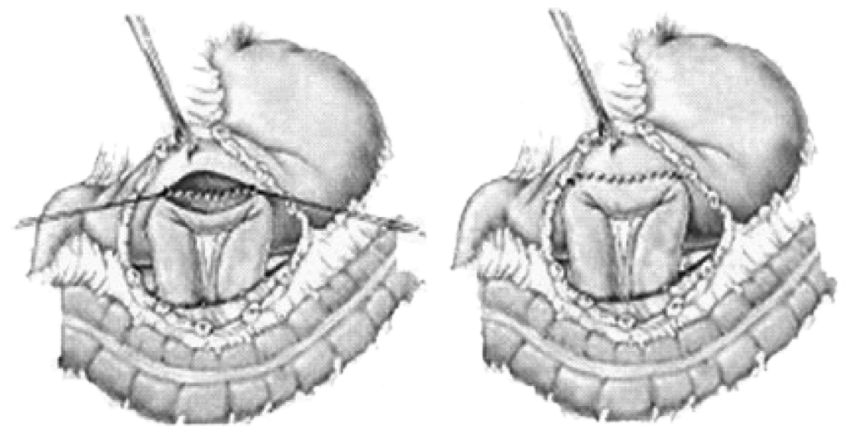

FIGURE 1 - The classic latero-lateral gastroenteroanastomosis

The objective of this study is a retrospective analysis of patients with stenosing, unresectable and advanced gastric adenocarcinoma, performing Rouxen-Y anastomosis.

\section{METHODS}

From January / 1998 to December / 2009 it was reviewed 62 patients with advanced and unresectable gastric adenocarcinoma, submitted to an elective latero-lateral Roux-en-Y gastrojejunoanastomosis (Figure 2). The age varied from 42 to 82 years (57.2 year-old average), and 43 were male (69.3\%). All of the cases presented important gastric stasis and vomits, making difficult the ingestion of any king of foods. Nine cases (14,5\%) presented hepatic metastasis. Preferentially the gastrojejunal anastomosis was pre-colic, in the great curvature and in the posterior wall of the stomach, in an area free from neoplasia. The jejunojejunoanastomosis was end-to-side anastomosis, about $50 \mathrm{~cm}$ from the stomach. In 14 cases (22.5\%) the anastomosis were made in the anterior wall of the great curvature. One case previously submitted the latero-lateral gastrojejunastomosis, it was re-operated in $10^{\text {th }}$ day due to uncontrollable bilious vomits, performed Rouxen-Y reconstruction, with significant improvement of the alimentary ingestion. There were no fistulas and no mortality. The figures 3, 4, 5, 6 and 7 show the technique of the anastomosis.

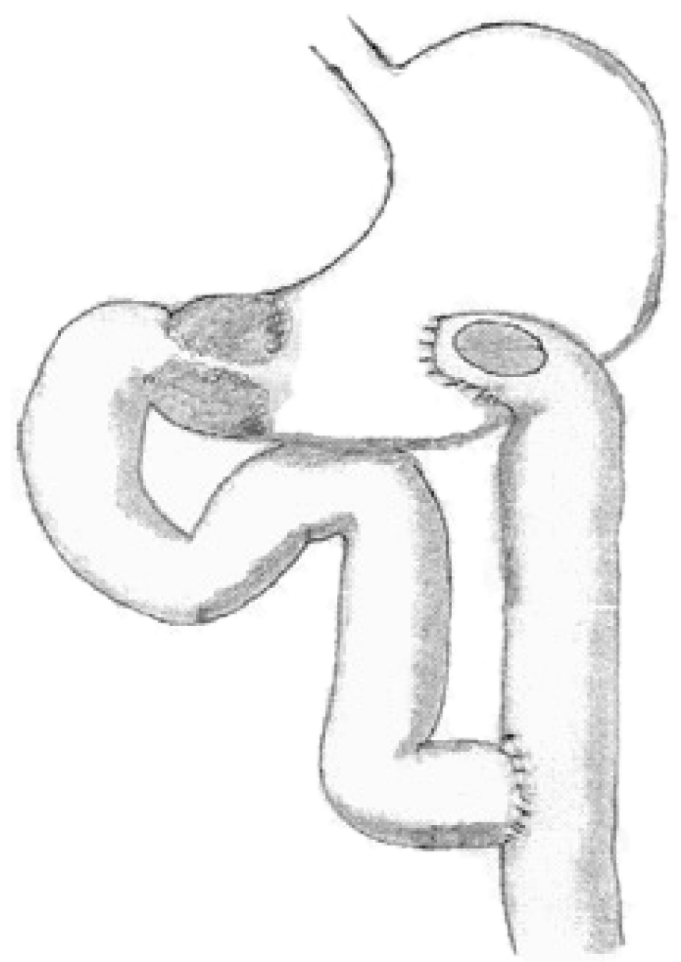

FIGURE 2 - Roux-en-Y gastroenteroanastomosis

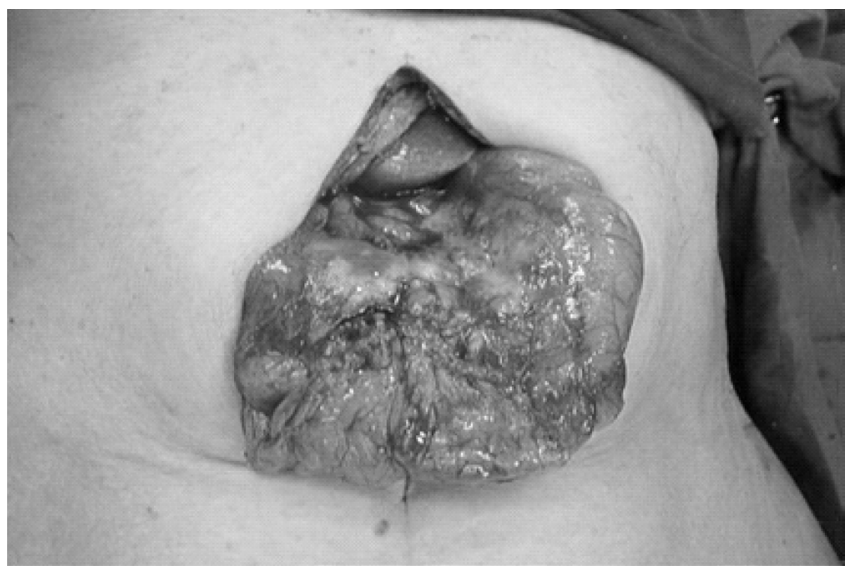

FIGURE 3 - Advanced and stenosing tumour of the gastric antrum. 


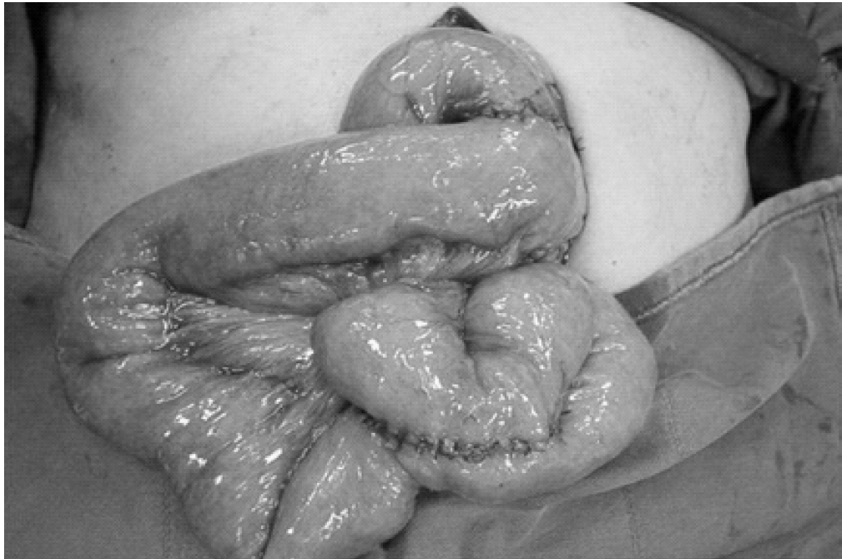

FIGURE 4 - Latero-lateral gastrojejunoanastomosis and the jejunojejunoanastomosis

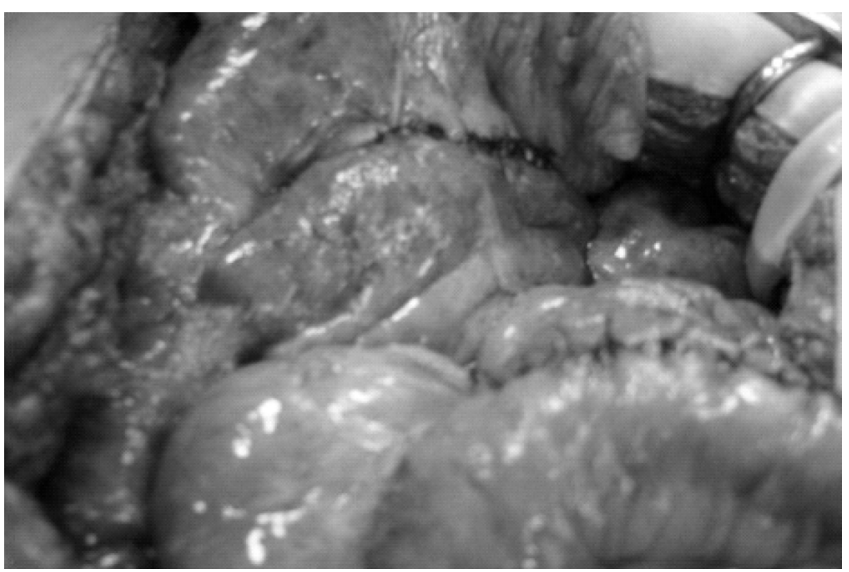

FIGURE 5 - Gastrojejunoanastomosis made at posterior wall of the stomach, and the jejunoanastomosis

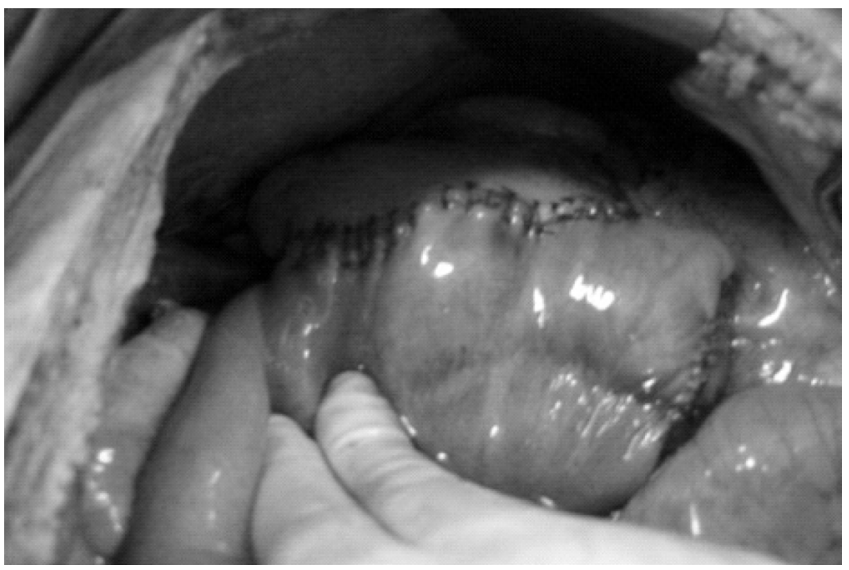

FIGURE 6 - Final aspect of the latero-lateral gastroenteroanastomosis

RESULTS

After surgery, liquids were introduced in the second or third postoperative day, and the major part of patients were discharged on sixth or seventh day. The medium period of hospitalization was of 7.5 days.

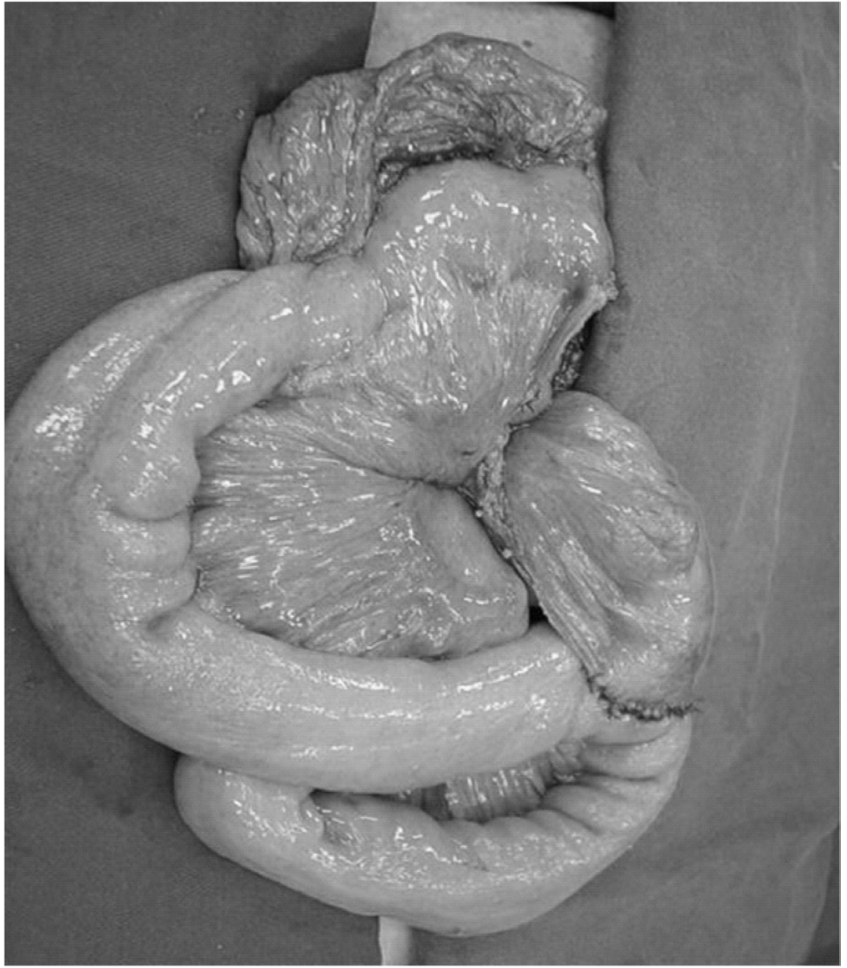

FIGURE 7 - Gastroenteroanastomosis and the jejunojejunoanastomosis

One death was recorded (1.6\%), secondary to the pneumonia and sepsis.

Later, all patients ingested foods and pastes with weight gain. However, 12 cases (19.3\%) they still referred abdominal fullness. The occurrence of frequent vomits was referred by four patients (6.4\%), getting better with ingestion of liquid feeding. The chemotherapy was indicated in 47 cases (75\%). The follow-up varied from three months to 26 months, and until the moment the medium survival was of 11 months.

\section{DISCUSSION}

Gastric cancer is a serious disease that sometimes has a rapid progression and its diagnosis is confirmed at an advanced stage. About $50 \%$ of all cases do not permit a curative procedure and a palliative surgery is necessary method to improve life quality ${ }^{1,6,7}$.

There are many options of palliative treatment in advanced gastric cancer: gastrostomy, jejunostomy, total gastrectomy or sub-total gastrectomy with only tumour resection and bypass ${ }^{4,6}$. Uslar et $\mathrm{al}^{6}$. analyzed a gastrectomy as a palliative treatment in patients diagnosed with an advanced gastric cancer. They showed that mean medium period of hospitalization was 17 days, morbidity 5,6\%, mortality $18 \%$ and medium survival 4,7 months.

Restitution of digestive tract after gastrectomy can be performed by three techniques: Billroth I, Billroth II and Roux-en-Y. D'Amato et al. ${ }^{7}$ comparing the three 
procedures demonstrated that Roux-en-Y anastomosis offers better results, including lower percentage of reflux esophagitis, chronic superficial gastritis and gastro-esophageal reflux. The authors choose Rouxen-Y as the technique of choice of reconstruction.

The advantages of Roux-en-Y reconstruction after a distal gastrectomy include a reduction of reflux gastritis and esophagitis, a decreased probability of gastric cancer recurrence, and a reduction in the incidence of surgical complications. The disadvantages of Roux-en-Y reconstruction include the possible development of stomal ulcer, an increased probability of cholelithiasis, increased difficulty with an endoscopic approach to the Vater's ampulla, and the possibility of Roux stasis syndrome ${ }^{8,9,10,11}$. And the authors recorded also an effective reducing of enteric reflux to the stomach and Helicobacter pylori infection ${ }^{10}$.

Some publications in the past emphasized that the Roux-en-Y reconstruction causes delayed gastric emptying, called Roux stasis syndrome. However in this series, the majority of patients referred they could eat solid and pasty food easily $11,12,13$.

According to the results of this study, in which a Roux-en-Y anastomosis was performed, a shorter period of hospitalization (7.5 days), lower mortality (1.6\%) and longer survival (medium 9 months) were observed. Were not found in the literature no publications focusing on this specific technique of gastric drainage, therefore, did not allow any comparison of results.

\section{CONCLUSIONS}

The Roux-en-Y gastrojejunoanastomosis is a good option in the sense of preventing the occurrence of vomits and regurgitations of enteric, bilious and pancreatic secretions in the postoperative period of palliative surgeries, in the stenosing and advanced gastric adenocarcinoma, improving they life quality, weight gaining.

\section{REFERENCES}

1. Chan DC, Fan YM, Lin CK, Chen CJ, Chen CY, Chao YC. Roux-en-Y reconstruction after distal gastrectomy to reduce enterogastric reflux and helicobacter pylori infection. J Gastrointest Surg 2007;11:1732-1740.

2. D'Amato A, Montesani C, Cristaldi M, Giovannini C, Pronio A, Santella S, Ventroni G, Ronga G, Ribotta G. Restoration of digestive continuity after subtotal gastrectomy: comparison of the methods of Billroth I, Billroth II and Roux em Y. Randomised prospective study. Ann Ital Chir 1999; 70(1):51-56

3. Dutra RA, Araújo WM, Andrade JI. The effects of Roux-en-Y limb length on gastric emptying and enterogastric reflux in rats. Acta Cir Bras 2008;23(2):179-183.

4. Estimativa 2010 - Incidência de Câncer no Brasil / Instituto Nacional de Câncer - Rio de Janeiro: INCA, 2010. p. 98

5. Gustavsson S, Ilstrup DM, Morrison P, Kelly KA. Roux-en-Y stasis syndrome after gastrectomy. Am J Surg 1988;155:490-4.

6. Hoya Y, Mitsumori N, Yanaga K. The advantages and disadvantages of a Roux-en-Y reconstruction after a distal gastrectomy for gastric cancer. Surg Today 2009;39(8):647-51.

7. Jacob CE, Bresciani C, Gama-Rodrigues JJ, Yagi OK, Zilberstein B, Cecconello I. Behaviour of gastric cancer in brazilian population. ABCD Arq Bras Cir Dig 2009:22(1):29-32.

8. Jacob CE, Gama-Rodrigues J, Irya K, Bresciani CJC, Zilberstein B, Martins BC, Cecconello I. Câncer gástrico precoce: complicações e mortalidade após gastrectomia e linfadenectomia regrada Experiência com 178 casos em uma Instituição. ABCD Arq Bras Cir Dig 2006;19(4):146-152.

9. Lopes F, Reis AF, Côrtes BJW, Fabrini DS, Lima HR, Rocha LCG. Esofagojejunostomia após gastrectomia total: anastomose mecânica ou manual? Rev Col Bras Cir. 2008;35(5):298-303.

10. Machi J, Takeda J, Kakegawa T. Tumores do estômago e do duodeno. In: Coelho J. Aparelho Digestivo: Clínica e Cirurgia. São Paulo: Atheneu; 2006. P.600-21.

11. Nunobe $S$, Okaro A, Sasako M, Saka M, Fukagawa T, Katai H, Sano T. Billroth 1 versus Roux-en-Y reconstructions: a quality-of-life survey at 5 years. Int J Clin Oncol 2007;12:433-439.

12. Sah BK, Chen MM, Yan M, Zhu ZG. Gastric cancer surgery: Billroth I or Billroth II for distal gastrectomy? BMC Cancer $2009 ; 9: 428$.

13. Songun I, Putter $H$, Kranenbarg EM, Sasako M, van de Velde CJ. Surgical treatment of gastric cancer: 15-year follow-up results of the randomised nationwide Dutch D1D2 trial. Lancet Oncol. 2010;11(5):439-49.

14. Uslar RA. Zúñiga CT, Seguel ES. Total palliative gastrectomy Rev Chil Cir 2002;54(2):143-7. 